\title{
Agglutination of lung surfactant with glucan
}

\author{
A J De Lucca II, K A Brogden, A D French
}

\begin{abstract}
Respirable cotton dust, implicated in the pathogenesis of byssinosis, contains a number of bioactive compounds. These include lipopolysaccharide (LPS), tannins, bacterial peptides, byssinosin, iacinilene $C$, and $1,3-\beta$-Dglucan. The exact aetiological agent of byssinosis in such dust has not been definitively identified nor has its mechanism of action on lower lung surfaces been determined. In the present study 1,3- $\beta$-D-glucan, Enterobacter agglomerans LPS, and ovine pulmonary surfactant were mixed in varying combinations. After incubation, their characteristics were determined by sucrose density centrifugation, TLC, and carbohydrate analysis. Precipitates were found in mixtures containing surfactant-glucan and surfactantglucan-LPS, but not in surfactant-LPS. Precipitates were not seen in the surfactant, LPS, and glucan controls. The formation of a precipitate did not increase the density of the surfactant glucan mixture when compared by density gradient centrifugation with the surfactant control. The interaction between surfactant and glucan was analysed by molecular modelling. The energy of a surfactant-glucan complex $(60.07 \mathrm{kcal} / \mathrm{mol})$ was calculated to be much lower than the sum of glucan $(47.09 \mathrm{kcal} / \mathrm{mol})$ and surfactant $(30.98$ kcal/mol) when added separately. The results indicate that 1,3- $\beta$-D-glucan does interact with surfactant and this complex may play a part in the pathogenesis of byssinosis by altering lung physiology maintained by pulmonary surfactant.
\end{abstract}

(British Journal of Industrial Medicine 1992;49:755-760)

$1,3-\beta$-D-Glucan is a polysaccharide that is present in the cell walls of fungi, bacteria, plants, and algae. ${ }^{1}$ It

Southern Regional Research Center, USDA, ARS, New Orleans, LA 70124, USA

A J De Lucca, A D French

National Animal Disease Center, USDA, ARS, Ames IA 50010, USA

K A Brogden crystallises in a triple helix structure and has structural functions in plants and fungi. ${ }^{2}$ In mammals, this glucan is biologically active and has been shown to stimulate the reticuloendothelial system (RES) and induce inflammation. ${ }^{3}$ Inhalation of glucans can have an adverse effect on the respiratory system. For example, Rylander $e t$ al found that glucan influenced the cell kinetics of the airways and lung walls and may be the cause of acute reactions found after chronic exposure to organic dusts.

Byssinosis, a pulmonary disease, results from the inhalation of airborne organic dusts during the processing of cotton, flax, or hemp fibres..$^{5-7}$ Although neither the exact aetiological agent(s) nor pathogenesis of byssinosis are known, we believe that the impact of inhaled dust upon pulmonary surfactant, which is the extracellular lining in the alveoli, may be an early step in the disease process. It is there that all or some of the bioactive agents in the inhaled dusts may interact with surfactant, thereby compromising surfactant function. This interaction could play a part in the byssinosis syndrome that is characterised by chest tightness on the first day of the work week accompanied by an impairment in function. ${ }^{8}$ Fever with influenza-like symptoms may occur on the first occasion of exposure and can reappear after a prolonged absence from work after a heavy exposure. ${ }^{8}$ Pulmonary impairment is due to bronchoconstriction.

Research has indicated that Gram negative bacterial lipopolysaccharide (LPS) present in respirable raw cotton dust ${ }^{79}$ plays an important part in this disease; $;^{61011}$ LPS causes pathophysiological changes, ${ }^{12}$ recruitment of neutrophils, and stimulation of platelet activating factor by alveolar macrophages. ${ }^{13}$ Incubation of purified Enterobacter agglomerans LPS with pulmonary surfactant has been shown to increase both the density and surface tension of surfactant ${ }^{14}$ similar to that with surfactant incubated with LPS from other bacterial species. ${ }^{15} 16$ The interaction of surfactant with $E$ agglomerans LPS is not as dramatic as that seen when surfactant is incubated with an aqueous extract of cotton dust. ${ }^{17}$ The cotton dust extract not only increases the surface tension of surfactant but also results in precipitation of the surfactant ${ }^{17}$ Bioactive compounds are found in cotton dust. They include LPS, tannins, bacterial peptides, iacinilene $C$, and $1,3-\beta$-D-glucan. ${ }^{18} 19$

In earlier research we have shown that an unknown compound(s) in cotton dust altered lung surfactant 
more severely than LPS. $^{17} 1,3-\beta$-D-Glucan is present in raw cotton dust and has been shown to cause inflammation and stimulation of the RES, and to activate macrophages. ${ }^{3}$ The purpose of this research was to investigate the effect of this glucan on lung surfactant and to determine whether the agglutination of lung surfactant in our previous research could be due to this glucan. Such an effect could suggest a role for $1,3-\beta-D$-glucan in the development of the byssinosis syndrome.

\section{Methods}

Surfactant, recovered by lavage of excised lungs from 12 healthy adult sheep, was prepared as described previously. ${ }^{20}$ An aliquot of the supernatant was extracted for phospholipid analysis of the surfactant by the method of Bligh and Dyer ${ }^{21}$ and analysed by high performance liquid chromatography (HPLC; Ultrasphere Si column, Beckman Instruments Inc, San Ramon, CA; pump 2350 and V4 absorbance detector, ISCO Inc, Lincoln, NB). The composition of phospholipids was typical of that reported for surfactant from sheep. ${ }^{21}$ Surfactant was freeze dried and stored in a refrigerator until needed.

Lipopolysaccharide (LPS) was extracted from Enterobacter agglomerans ATCC 27996 cells (32.6 g dry weight) by the hot water phenol method. ${ }^{22}$ The combined water extracts containing the crude LPS were dialysed against distilled water at $4^{\circ} \mathrm{C}$ for four days and centrifuged (5000 g) to remove any insoluble particles. The LPS solution was diafiltered

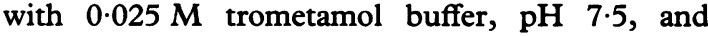
concentrated to $180 \mathrm{ml}$ (YM 10; Amicon Corp, Danvers, MA). RNase A (type 111A; Sigma Chemical Co, St Louis, MO) and DNase I (Sigma Chemical Co) were added to the solution at a final concentration of $100 \mu \mathrm{g} / \mathrm{ml}$ and $10 \mu \mathrm{g} / \mathrm{ml}$ respectively and incubated at $37^{\circ} \mathrm{C}$ in a water bath for 30 minutes. Trypsin (Worthington Biochemical Group, Bedford, MA) was then added to a final concentration of $10 \mu \mathrm{g} / \mathrm{ml}$ and incubated for one hour in a $37^{\circ} \mathrm{C}$ water bath. Purification of the LPS was performed by a modification of the alcohol precipitation method described earlier. ${ }^{23}$ The LPS solution was added slowly to chilled absolute ethanol containing $0.02 \%$ sodium acetate $(0.1 \mathrm{ml}$ of $2.0 \%$ sodium acetate per 10 $\mathrm{ml}$ of total ethanol-LPS volume) in an icebath (1:9, vol:vol). The precipitated LPS was allowed to sit overnight in the alcohol at $4^{\circ} \mathrm{C}$. The LPS suspension was centrifuged $(4000 \mathrm{~g})$ at $4^{\circ} \mathrm{C}$. Pelleted LPS was dissolved in a minimum of sterile, pyrogen free water and precipitated as before. After overnight storage at $4^{\circ} \mathrm{C}$ the LPS suspension was centrifuged and stored lyophilised.

Purified 1,3- $\beta$-D-glucan was purchased (Wako Chemicals USA, Inc, Richmond, VA). The glucan was depyrogenated by stirring and dissolving $60 \mathrm{mg}$ of the glucan in $30 \mathrm{ml}$ of $0.05 \mathrm{M} \mathrm{NaOH} .^{24}$ After the glucan became solubilised, $0.6 \mathrm{~g}$ of depyrogenated activated charcoal was added. The mixture was stirred for 30 minutes and then sterilised by filtration through a $0.45 \mu$ filter unit.

Purified $E$ agglomerans LPS ( $2 \mathrm{mg} / \mathrm{ml}$ ) was suspended in 0.05 $\mathrm{M}$ trometamol buffer, $\mathrm{pH} 7.5$. Surfactant was suspended in the same buffer and at the same concentration as was the LPS. The depyrogenated glucan $(2 \mathrm{mg} / \mathrm{ml})$ as well as the aforementioned solutions were added together according to the protocol in table 1 . It should be noted that just before addition to the other reagents the $\mathrm{pH}$ of the glucan solution was reduced to 7.5 with $1 \mathrm{~N} \mathrm{HCl}$. The prepared mixtures were incubated in a $37^{\circ} \mathrm{C}$ waterbath for 30 minutes.

Sucrose density centrifugation was performed as previously described ${ }^{14} 17$ on another set of samples prepared as noted in table 1 to determine whether the glucan would alter the density of the surfactant and also to determine whether the glucan-surfactant complex was as tightly bound as the LPS surfactant complex in our earlier work. ${ }^{14}{ }^{17}$ After centrifugation the mixture in each tube was fractionated into $0.8 \mathrm{ml}$ aliquots. A lipid extraction ${ }^{21}$ followed by thin layer chromatography was performed on each aliquot to determine the presence of surfactant phospholipids.

Additional aliquots were resuspended in $10 \mathrm{ml}$ of $0.025 \mathrm{M}$ trometamol buffer, $\mathrm{pH} 7.0$, with $0.001 \%$ $\mathrm{NaN}_{3}$ and then centrifuged for 50 minutes at $27000 \mathrm{~g}$ at $4^{\circ} \mathrm{C}$. The supernatant was then discarded and the pellets were resuspended in distilled water and

Table 1 Assay protocol to study glucan reactivity with lung surfactant (component volumes in ml)

\begin{tabular}{|c|c|c|c|c|c|}
\hline Samples & Surfactant * & $\begin{array}{l}\text { Pyrogen free } \\
\text { water }\end{array}$ & Buffert & Glucan $\ddagger$ & LPS§ \\
\hline $\begin{array}{l}\text { Surfactant control } \\
\text { Glucan control } \\
\text { LPS control } \\
\text { SLS-Glucan } \\
\text { SLS-LPS } \\
\text { SLS-LPS-Glucan }\end{array}$ & $\begin{array}{l}\frac{1 \cdot 0}{-} \\
1 \cdot 0 \\
1 \cdot 0 \\
1 \cdot 0\end{array}$ & $\begin{array}{l}1 \cdot 0 \\
- \\
- \\
-\end{array}$ & $\begin{array}{l}2 \cdot 0 \\
2 \cdot 0 \\
2 \cdot 0 \\
1 \cdot 0 \\
1 \cdot 0 \\
1 \cdot 0\end{array}$ & $\begin{array}{l}\frac{\overline{2}}{2 \cdot 0} \\
\frac{2 \cdot 0}{1 \cdot 0}\end{array}$ & $\begin{array}{l}\overline{-} \\
2 \cdot 0 \\
\frac{-}{2 \cdot 0} \\
1 \cdot 0\end{array}$ \\
\hline
\end{tabular}

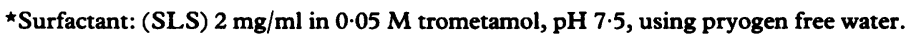

†Buffer: $0.05 \mathrm{M}$ trometamol, pH 7.5, using pyrogen free water.

fGlucan: $2 \mathrm{mg} / \mathrm{ml}$ dissolved in pyrogen free water $(\mathrm{pH} \mathrm{12.5)}$ then $\mathrm{pH}$ changed to 7.5 before addition to sample tube.

§LPS: Purified Enterobacter agglomerans LPS, $2 \mathrm{mg} / \mathrm{ml}$ in $0.05 \mathrm{M}$ trometamol, pH 7.5. 
centrifuged as before. The pelleted samples were then analysed for the presence of carbohydrate. ${ }^{25}$

The interaction between the surfactant and glucan was also examined in a molecular modelling study. A model of the glucan was optimised ${ }^{26}$ with the molecular mechanics model MM3 (Technical Utilisation Corporation, Inc, Glenn Village Court, Powell, Ohio, 43065). Chem X (Chemical Design Ltd, Oxford, England) was used to prepare the input file for MM3 and to display the output figures. The molecular modelling study was performed on a MicroVAX 3100 computer. The function of MM3 is to minimise the potential energy of a molecule or group of molecules through adjustment of the individual atomic coordinates. Input for the program consists of a list of the coordinates for each atom and a list of the connectivities. Molecular mechanics energy calculations generally consist of bond stretching, bond angle bending, torsional and non-bonded terms. Model MM3 is considered to have a complex calculation of molecular mechanics energy, with many refinements, such as correction for increased bond length at some torsional positions. Also, it uses a Morse-like potential for bond stretching rather than the simple harmonic term often used. The program is applicable to carbohydrates with special consideration for anomeric effects and hydrogen bonding. ${ }^{26}$ The calculations were carried out at a dielectric constant of 1.5 (the program default) and the energy minimisation routine was used rather than the geometry optimisation technique that has been less reliable in our hands. Energy values reported are the final steric energy values of the program. These values could be converted to heat of formulation values by addition to strainless bond energy values but were not. Values for MM3 energy are especially sensitive to the dielectric constant used, and energy values at other dielectric constants may lead to alternative conclusions.

The starting coordinates were from six glucose residues of a single strand of the triple helical structure of glucan from a published diffraction study. ${ }^{1}$ A model of the lung surfactant phospholipid was prepared similarly, except that the published crystal structure coordinate ${ }^{27}$ used to generate the model were ambiguous concerning the location of single and double bonds. Further, the phosphate group required parameters not available in $M M 3$ for the particular pattern deemed most likely. Therefore, a simplified phospholipid molecule was used, based loosely on the crystallographic coordinates but with the phosphate group removed. To prepare a helical complex, the optimised glucan helix was opened by changing the torsion angle $\mathrm{C} 2-\mathrm{C} 3-\mathrm{O} 3-\mathrm{Cl}^{\prime}$, and the lipid model was moved into the resulting gap between the third and fourth residues, aligning it roughly with the helix axis.

Optimisation of the model glucan-surfactant

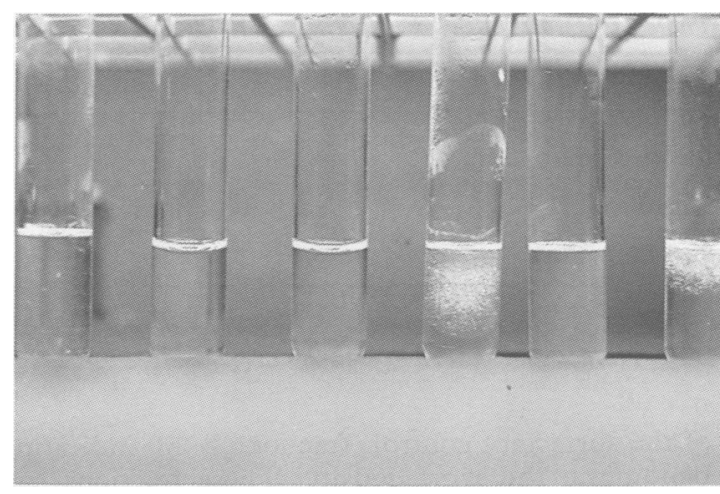

Figure 1 Tubes containing mixtures of compounds as outlined in table 1 . From left to right: lung surfactant control, 1,3- $\beta$-D-glucan control, LPS control, lung surfactant-glucan mixture, surfactant-LPS mixture, surfactant-LPS-glucan mixture.

complex required several hours of cpu time. Output from the program consists of the optimised atomic coordinates and the calculated energy. After conversion with a local program, these coordinates were read into the CHEM-X program for display of the structures.

\section{Results}

After incubation of the mixtures prepared as in table 1 , precipitates were seen only in the tubes containing surfactant-glucan and surfactant-LPS-glucan (figs 1 and 2). Precipitates were not seen in the tube containing surfactant-LPS or in the surfactant, LPS, or glucan controls.

Table 2 shows the sucrose gradient centrifugation results. The phospholipid (indicating the presence of surfactant) of the surfactant-glucan mixture was present in the same sucrose gradient fractions as that

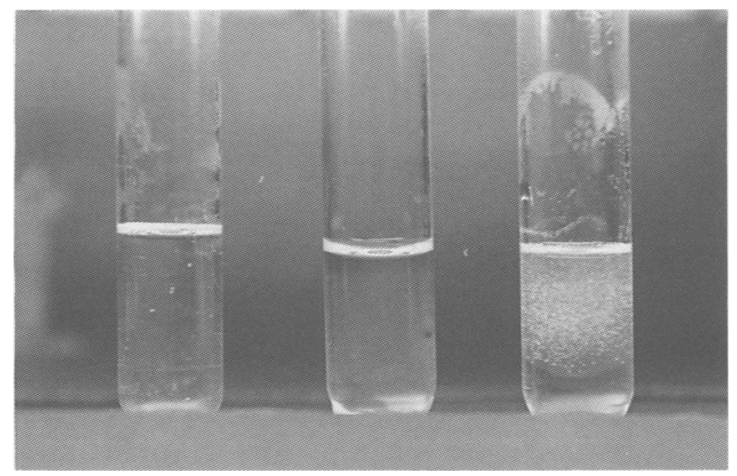

Figure 2 Close up photograph showing from left to right: lung surfactant control, $1,3-\beta-D$-glucan control, lung surfactant-glucan mixture. 
Table 2 Results of sucrose gradient centrifugation of incubated samples

\begin{tabular}{|c|c|c|}
\hline Sample & Surfactant fraction (carbohydrate) & Pellet fraction (carbohydrate) \\
\hline $\begin{array}{l}\text { Surfactant control* } \\
\text { Glucan control } \dagger \\
\text { LPS control } \neq \\
\text { SLS-glucan } \\
\text { SLS-LPS } \\
\text { SLS-LPS-glucan }\end{array}$ & $\begin{array}{l}7-20(1 \mu \mathrm{g}) \\
- \\
\overline{7-20}(1 \mu \mathrm{g}) \\
3-12(56 \mu \mathrm{g}) \\
3-12(24 \mu \mathrm{g})\end{array}$ & $\begin{array}{l}\overline{26}(>350 \mu \mathrm{g}) \\
\overline{26}(>550 \mu \mathrm{g}) \\
\overline{26}(>300 \mu \mathrm{g})\end{array}$ \\
\hline
\end{tabular}

*Surfactant: SLS, $2 \mathrm{mg} / \mathrm{ml}$ in $0.05 \mathrm{M}$ trometamol, $\mathrm{pH} \mathrm{7.5,} \mathrm{in} \mathrm{pyrogen} \mathrm{free} \mathrm{water.}$

†Glucan: $2 \mathrm{mg} / \mathrm{ml}$ in pyrogen free water $(\mathrm{pH} 12.5)$. $\mathrm{pH}$ changed to 7.5 before addition to other sample tubes.

$\ddagger$ LPS: Purified Enterobacter agglomerans lipopolysaccharide, $2 \mathrm{mg} / \mathrm{ml}$ in $0.05 \mathrm{M}$ trometamol, pH 7.5.

of the surfactant control (fractions 7-20) indicating banding at the same density. These fractions had only trace amounts of carbohydrate, indicating that glucan was not present. The results show that the glucan was present only in the pelleted material (fraction 26).

Phospholipids of the surfactant-LPS mixture were found in a different fraction group (fractions 3-12) than the surfactant control. No pellet was found in the surfactant-LPS sample.

Similarly, phospholipids of the surfactant-LPSglucan mixture were also found in fractions 3-12. In this mixture, however, a pellet was present in the same fraction as in the glucan control. The pellets, all of which contained large amounts of carbohydrate, were found only in samples containing glucan.

Figure 3 shows the molecular structure of the glucan and the phospholipid. The helical configuration of the six glucose residues of the glucan is apparent as are the unsubstituted chains of the phospholipid.

The energy values calculated by the MM3 program for the glucan and surfactant were 47.09 and $30.96 \mathrm{kcal} / \mathrm{mol}$ respectively (table 3 ). The energy of the surfactant-glucan mixture $(60.07 \mathrm{kcal} / \mathrm{mol})$ was much lower than the sum of the two compounds separately $(77 \cdot 78 \mathrm{kcal} / \mathrm{mol})$. This indicates molecular

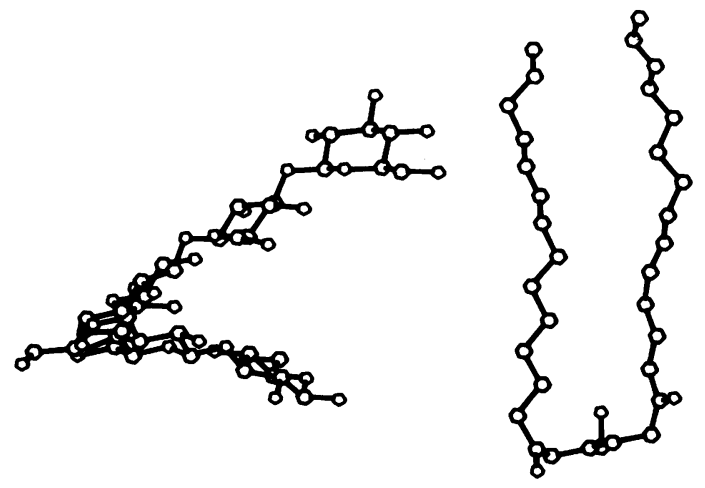

Figure 3 MM3 computer modelling program representation of (on left) $1,3-\beta-D-$ glucan, (on right) lung surfactant phospholipid. interaction. Figure 4 shows the calculations for the interaction of the glucan and surfactant.

\section{Discussion}

The present research is part of a series of studies to examine the individual effects of major bioactive components in raw cotton dust on pulmonary surfactant. Surfactant is the initial pulmonary surface that small inhaled particles, dust, and microorganisms contact upon entering the alveoli. The binding of cotton dust to surfactant in the lung may change the biophysical characteristics, and hence the physiological properties, of surfactant. Such a cascade of events may play a part in the pathogenesis of byssinosis.

In the present study, mixtures of purified $E$ agglomerans LPS and ovine pulmonary surfactant had biophysical characteristics that have been seen before. For example, the increase in density of the surfactant-LPS mixture as compared with the surfactant control was similar to that in a previous study. ${ }^{14}$ Also, the current results suggest that precipitation of lung surfactant by an aqueous extract of raw cotton dust seen in our earlier work ${ }^{17}$ is due to the 1,3- $\beta$-D-glucan present in raw cotton dust.

Comparison of the sucrose gradient data showed that the surfactant-glucan mixture separated during density gradient centrifugation and buoyed at the densities of each component separately. The surfactant-LPS mixture did not dissociate and buoyed at a density greater than that of the surfactant control. The differences in the amount of carbohydrate present in the fractions also containing phospholipid in the SLS-glucan, SLS-LPS, and SLS-LPS-

Table 3 Energy values for glucan model, lung surfactant phospholipid model and complex of both

\begin{tabular}{lc}
\hline Sample & $\begin{array}{l}\text { MM3 energy values } \\
\text { (dielectric } 1 \cdot 50)\end{array}$ \\
\hline Glucan alone & $47.09 \mathrm{kcal} / \mathrm{Mol}$ \\
Lung phospholipid alone & $30.96 \mathrm{kcal} /$ Mol \\
Total energy of components added together & $77.78 \mathrm{kcal} / \mathrm{Mol}$ \\
Calculated energy of complex & $60.07 \mathrm{kcal} / \mathrm{Mol}$ \\
Energy difference between separate & $-17.71 \mathrm{kcal} / \mathrm{Mol}$ \\
\hline components and complex & \\
\hline
\end{tabular}




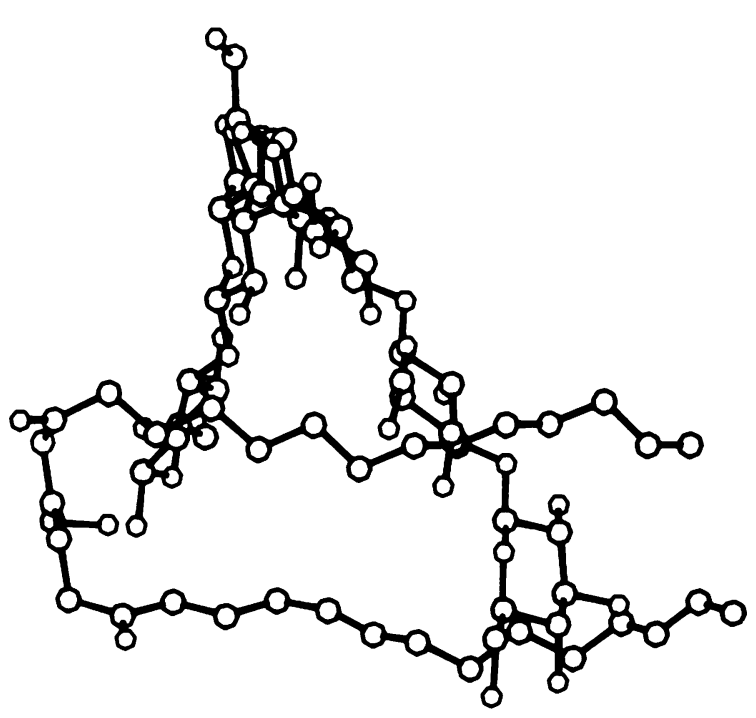

Figure 4 MM3 computer modelling program showing interaction of 1,3- $\beta-D-$ glucan with lung surfactant phospholipid.

glucan mixtures indicate that glucan bound to surfactant and reduced the amount of LPS that could bind during the incubation step. When centrifuged, the glucan dissociated from the complex leaving a lesser amount of carbohydrate in the SLS-LPS-glucan mixture than in the SLS-glucan mixture. These data, as well as the agglutination of the surfactant by the glucan, indicate that both the LPS and glucan bound to the surfactant during the incubation step. The surfactant-glucan complex was broken, however, by the stress of passing through the sucrose gradient. This suggests that the surfactant-glucan bonding is weak (van der Waals forces or hydrogen bonding) whereas that for the surfactant-LPS complex is not.

The values generated by the $M M 3$ molecular modelling program show that the surfactant-glucan complex is feasible and has a lower energy level than that for the two separate compounds added together. It also indicates that the interaction between the two compounds is neither of a covalent nature nor due to a mechanical "intrapment" of the molecules. The data suggest that the interaction between the glucan and lung surfactant is due to van der Waals or hydrogen bonding. Dimensionally, the surfactant phospholipid fits snugly through the helical structure of the glucan molecule, but this may not be a strong association.

The mechanism of interaction between glucans and surfactant on the alveolar surface is not clear. It is probable that the reaction between glucan and surfactant phospholipids will not occur on a one to one basis as suggested by the model. Glucans will be in large aggregates and phospholipids will be in hydrophobic-hydrophilic layers with the apolar groups facing each other. Interactions of phospholipids with glucans will depend upon the orientation of the surfactant as it lines the alveolar epithelium.

Changes in surfactant and surfactant synthesis have been documented in other respiratory diseases. ${ }^{2829}$ These changes are mediated by microbial products or oedema components directly on secreted surfactant or indirectly through changes in metabolism of type II epithelial cells. ${ }^{29}$ It is possible that alteration of surfactant function also plays a part in the pathogenesis of byssinosis by either of two mechanisms. The data from the present work suggest that $1,3-\beta$-D-glucan, a constituent of raw cotton dust, can agglutinate lung surfactant in vitro. Inhalation of this glucan could have a similar effect in vivo. This, in turn, could induce abnormalities in surface tension. Such abnormalities result in significant changes in both the quantitative and qualitative amounts of lung surfactant. ${ }^{30-32}$ Similar dysfunctions may also result in some of the symptoms seen in the byssinosis syndrome.

Requests for reprints to: A J De Lucca II, Composition and Properties Research Unit, Southern Regional Research Center, USDA, ARS, 1100 Robert E Lee Blvd, New Orleans, LA 70124 USA.

1 Deslandes Y, Merchessault RH, Sarko A. Triple-helical structure of (1-3)- $\beta$-D-glucan. Macromolecules 1980;13:1466-71.

2 Marchessault RH, Deslandes Y. Fine structure of (1-3)- $\beta$-Dglucans: curdlan and paraylon. Carbohydr Res 1979;75: $231-42$.

3 Di Luzio NR. Lysozyme, glucan-activated macrophages and neoplasia. Journal of the Reticuloendothelial Society 1979;26:67-81.

4 Rylander R, Goto H, Marchant B. Acute toxicity of inhaled beta, 1-3 glucan and endotoxin. In: Jacobs RR, Wakelyn PJ, eds. Proceedings 13th cotton dust research conference. 1989 Beltwide cotton research conferences. Nashville, Tennessee: National Cotton Council, 1989:145-6.

5 Fischer JJ, Kylberg K. Microbial flora associated with cotton plant parts and the air of cotton mills. In: Wakelyn PJ, Jacobs $\mathrm{RR}$, eds. Proceedings seventh cotton dust research conference. 1983 Beltwide cotton production research conferences. San Antonio, Texas: National Cotton Council, 1983:36-7.

6 Pervis B, Vigiliani EC, Cavagna C, Finulli M. The role of bacterial endotoxins in occupational diseases caused by inhaling vegetable dusts. $\mathrm{Br} J$ Ind Med 1961;18:120-9.

7 Tuffnell P. The relationship of byssinosis to the bacteria and fungi in the air of textile mills. Br $J$ Ind Med 1960;17:304-6.

8 Rylander R, Schilling RSF, Pickering CAC, Rooke GB, Dempsey AN, Jacobs RR. Effects after acute and chronic exposure to cotton dusts: the Manchester criteria. $\mathrm{Br} J$ Ind Med 1987;44:577-9.

9 Cinkotai FF, Whitaker CJ. Airborne bacteria and the prevalence of byssinotic symptoms in 21 cotton spinning mills in Lancashire. Ann Occup Hyg 1978;21:239-50.

10 Castellan RM, Olenchock SA, Hankinson JL, et al. Acute bronchoconstriction induced by cotton dust: dose-related response to endotoxin and other dust factors. Ann Intern Med 1984;101:157-63.

11 Petsonk EL, Olenchock SA, Castellan RM, et al. Human ventilatory response to washed and unwashed cottons from different growing areas. Br J Ind Med 1986;43:182-7.

12 Bottoms GD, Johnson M, Ward D, Fessier J, Lamar C, Turek J. 
Release of eicosanoids from white blood cells, platelets, smooth muscle cells, and endotoxin and A 23187. Circ Shock 1986;20:25-34.

13 Rylander R, Beijer L. Inhalation of endotoxin stimulates alveolar macrophage production of platelet-activating factor. Am Rev Respir Dis 1987;135:83-5.

14 De Lucca II, AJ, Brogden KA, Engen R. Enterobacter agglomerans lipopolysaccharide-induced changes in pulmonary surfactant as a factor in the pathogenesis of byssinosis. $J$ Clin Microbiol 1988;36:41-7.

15 Brogden KA, Cutlip RC, Lehmkuhl HD. Complexing of bacterial lipopolysaccharide with lung surfactant. Infect Immun 1986;52:644-9.

16 Brogden KA, Rimler RB, Cutlip RC, Lehmkuhl HD. Incubation of Pasteurella haemolitica and Pasteurella multocida lipopolysaccharide with sheep lung surfactant. Am J Vet Res 1986;47:727-9.

17 De Lucca II, AJ, Brogden KA, Catalano EA, Morris NM Biophysical physical alteration of lung surfactant by extracts of cotton dust. Br J Ind Med 1991;48:41-7.

18 Specks V, Kresfsky TJ, Limper AH, Brutinel WM, Rohrbach MS. Tannin mediates the secretion of neutrophil chemotactic factor from alveolar macrophages in rabbits and humans. In: Jacobs RR, Wakelyn PJ, eds. Proceedings 13th cotton dust research conference. 1989 Beltwide cotton research conferences. Nashville, Tennessee: National Cotton Council, 1989:79-81.

19 Jacobs RR. Review of the etiology and pathogenesis of byssinosis: historical perspective. In: Wakelyn PJ, Jacobs RR, eds. Proceedings seventh cotton dust research conference. 1983 Beltwide cotton production research conferences. San Antonio, Texas: National Cotton Council, 1983:7-10.

20 Jobe A, Ikegami M, Glatz T, Yoshida Y, Diakomanozis E, Padbury J. Duration and characteristics of treatment of premature lambs with natural surfactant. J Clin Invest $1981 ; 677: 370-5$.

21 Bligh EG, Dyer WJ. A rapid method of total lipid extraction and purification. Canadian Journal of Biochemistry and Physiology 1959;37:911-7.
22 Westphal O, Jann K. Bacterial lipopolysaccharides: extraction with hot phenol-water and further applications of the procedure. In: Whistler RL, Walfrom ML, eds. Methods in carbohydrate chemistry. Vol 5. New York: Academic Press, 1965:83-91.

23 Kato N, Ohta M, Kido N, Ito H, Naito S, Kuno T. Formation of a hexagonal lattice structure by an R-form lipopolysaccharide of Klebsiella sp. J Bacteriol 1985;162:1142-50.

24 Obayashi T. A new endotoxin-specific assay. Adv Exp Med Biol 1990;256:215-23.

25 Dubois M, Giles KA, Hamilton JK, Rebers PA, Smith F. Colorimetric method for determination of sugars and related substances. Anal Chem 1956;28:351-6.

26 Allinger NL, Rahman M, Lii J-H. A molecular mechanics force field (MM3) for alcohol and ethers. Journal of the American Chemical Society 1990;112:8293-8307.

27 Pascher I, Sundell S, Harlos K, Eibl H. Confirmation and packing properties of membrane lipids: The crystal structure of sodium dimyristoylphosphatidylglycerol. Biochimica et Biophysica Acta 1987;896:77-88.

28 Haagsman HP, van Golde LMG. Lung surfactant and pulmonary toxicology. Lung $1985 ; 163: 275-303$.

29 Brogden KA. Changes in pulmonary surfactant during bacterial pneumonia. Antonie von Leeuwenhoek 1991;59:215-23.

30 Petty TL, Reiss OK, Paul GW, Silvers GW, Elkins ND. Characteristics of pulmonary surfactant in adult respiratory distress syndrome associated with trauma and shock. Am Rev Respir Dis 1977;115:531-6.

31 von Wichert P, Kohl FV. Decreased dipalmitoyl lecithin content found in lung specimens from patients with so-called shocklung. J Int Care Med 1977;3:27-30.

32 Hallman M, Spragg R, Harrell HA, Moser KM, Gluck L. Evidence of lung surfactant abnormality in respiratory failure. J Clin Invest 1982;70:673-83.

Accepted 17 February 1992 